\title{
On coupled fixed point theorems on partially ordered $G$-metric spaces
}

\author{
Erdal Karapınar ${ }^{1}$, Billûr Kaymakçalann ${ }^{2 *}$ and Kenan Taş̧
}

${ }^{\text {*Correspondence: }}$

billur@cankaya.edu.tr

${ }^{2}$ Department of Mathematics and

Computer Science, Çankaya

University, Ankara, Turkey

Full list of author information is

available at the end of the article

\begin{abstract}
In this manuscript, we extend, generalize and enrich some recent coupled fixed point theorems in the framework of partially ordered $\mathrm{G}$-metric spaces in a way that is essentially more natural.

MSC: 46N40;47H10; 54H25; 46T99

Keywords: coupled fixed point; coincidence point; mixed $g$-monotone property; ordered set; G-metric space
\end{abstract}

\section{Introduction and preliminaries}

In [1] Aydi et al. established coupled coincidence and coupled common fixed point results for a mixed $g$-monotone mapping satisfying nonlinear contractions in partially ordered G-metric spaces. These results generalize those of Choudhury and Maity [2].

Here we generalize, improve, enrich and extend the above mentioned coupled fixed point results of Aydi et al.

Throughout this paper, let $\mathbb{N}$ denote the set of nonnegative integers, and $\mathbb{N}^{*}$ be the set of positive integers.

Definition 1.1 (See [3]) Let $X$ be a non-empty set, and $G: X \times X \times X \rightarrow \mathbb{R}^{+}$be a function satisfying the following properties:

(G1) $G(x, y, z)=0$ if $x=y=z$,

(G2) $0<G(x, x, y)$ for all $x, y \in X$ with $x \neq y$,

(G3) $G(x, x, y) \leq G(x, y, z)$ for all $x, y, z \in X$ with $y \neq z$,

(G4) $G(x, y, z)=G(x, z, y)=G(y, z, x)=\cdots$ (symmetry in all three variables),

(G5) $G(x, y, z) \leq G(x, a, a)+G(a, y, z)$ for all $x, y, z, a \in X$ (rectangle inequality).

Then the function $G$ is called a generalized metric or, more specially, a $G$-metric on $X$, and the pair $(X, G)$ is called a $G$-metric space.

Every $G$-metric on $X$ defines a metric $d_{G}$ on $X$ by

$$
d_{G}(x, y)=G(x, y, y)+G(y, x, x), \quad \text { for all } x, y \in X
$$

Example 1.2 Let $(X, d)$ be a metric space. The function $G: X \times X \times X \rightarrow[0,+\infty)$, defined by

$$
G(x, y, z)=\max \{d(x, y), d(y, z), d(z, x)\}
$$




$$
G(x, y, z)=d(x, y)+d(y, z)+d(z, x)
$$

for all $x, y, z \in X$, is a $G$-metric on $X$.

Definition 1.3 (See [3]) Let $(X, G)$ be a $G$-metric space, and let $\left\{x_{n}\right\}$ be a sequence of points of $X$. We say that $\left(x_{n}\right)$ is $G$-convergent to $x \in X$ if $\lim _{n, m \rightarrow+\infty} G\left(x, x_{n}, x_{m}\right)=0$, that is, for any $\varepsilon>0$, there exists $N \in \mathbb{N}$ such that $G\left(x, x_{n}, x_{m}\right)<\varepsilon$, for all $n, m \geq N$. We call $x$ the limit of the sequence and write $x_{n} \rightarrow x$ or $\lim _{n \rightarrow+\infty} x_{n}=x$.

Proposition 1.4 (See [3]) Let $(X, G)$ be a $G$-metric space. The following are equivalent:

(1) $\left\{x_{n}\right\}$ is G-convergent to $x$,

(2) $G\left(x_{n}, x_{n}, x\right) \rightarrow 0$ as $n \rightarrow+\infty$,

(3) $G\left(x_{n}, x, x\right) \rightarrow 0$ as $n \rightarrow+\infty$,

(4) $G\left(x_{n}, x_{m}, x\right) \rightarrow 0$ as $n, m \rightarrow+\infty$.

Definition 1.5 (See [3]) Let $(X, G)$ be a $G$-metric space. A sequence $\left\{x_{n}\right\}$ is called a $G$ Cauchy sequence if, for any $\varepsilon>0$, there is $N \in \mathbb{N}$ such that $G\left(x_{n}, x_{m}, x_{l}\right)<\varepsilon$ for all $m, n, l \geq$ $N$, that is, $G\left(x_{n}, x_{m}, x_{l}\right) \rightarrow 0$ as $n, m, l \rightarrow+\infty$.

Proposition 1.6 (See [3]) Let $(X, G)$ be a G-metric space. Then the following are equivalent:

(1) the sequence $\left\{x_{n}\right\}$ is G-Cauchy,

(2) for any $\varepsilon>0$, there exists $N \in \mathbb{N}$ such that $G\left(x_{n}, x_{m}, x_{m}\right)<\varepsilon$, for all $m, n \geq N$.

Proposition 1.7 (See [3]) Let $(X, G)$ be a G-metric space. A mapping $f: X \rightarrow X$ is $G$ continuous at $x_{0}$ if and only if it is G-sequentially continuous at $x_{0}$, that is, whenever $\left(x_{n}\right)$ is G-convergent to $x_{0}$, the sequence $\left(f\left(x_{n}\right)\right)$ is G-convergent to $f\left(x_{0}\right)$.

Definition 1.8 (See [3]) A $G$-metric space $(X, G)$ is called $G$-complete if every $G$-Cauchy sequence is $G$-convergent in $(X, G)$.

Definition 1.9 (See [2]) Let $(X, G)$ be a $G$-metric space. A mapping $F: X \times X \rightarrow X$ is said to be continuous if for any two $G$-convergent sequences $\left\{x_{n}\right\}$ and $\left\{y_{n}\right\}$ converging to $x, y$ respectively, $\left\{F\left(x_{n}, y_{n}\right)\right\}$ is $G$-convergent to $F(x, y)$.

Let $(X, \leq)$ be a partially ordered set and $(X, G)$ be a $G$-metric space, $g: X \rightarrow X$ be a mapping. A partially ordered $G$-metric space, $(X, G, \preceq)$, is called $g$-ordered complete if for each convergent sequence $\left\{x_{n}\right\}_{n=0}^{\infty} \subset X$, the following conditions hold:

$\left(O C_{1}\right)$ if $\left\{x_{n}\right\}$ is a non-increasing sequence in $X$ such that $x_{n} \rightarrow x^{*}$ implies $g x^{*} \preceq g x_{n}$, $\forall n \in \mathbb{N}$

$\left(O C_{2}\right)$ if $\left\{y_{n}\right\}$ is a non-decreasing sequence in $X$ such that $y_{n} \rightarrow y^{*}$ implies $g y^{*} \succeq g y_{n}$, $\forall n \in \mathbb{N}$.

Moreover, a partially ordered $G$-metric space, $(X, G, \preceq)$, is called ordered complete when $g$ is equal to identity mapping in the above conditions $\left(O C_{1}\right)$ and $\left(O C_{2}\right)$. 
Definition 1.10 (See [4]) An element $(x, y) \in X \times X$ is said to be a coupled fixed point of the mapping $F: X \times X \rightarrow X$ if

$$
F(x, y)=x \quad \text { and } \quad F(y, x)=y .
$$

Definition 1.11 (See [5]) An element $(x, y) \in X \times X$ is called a coupled coincidence point of a mapping $F: X \times X \rightarrow X$ and $g: X \rightarrow X$ if

$$
F(x, y)=g(x), \quad F(y, x)=g(y) .
$$

Moreover, $(x, y) \in X \times X$ is called a common coupled coincidence point of $F$ and $g$ if

$$
F(x, y)=g(x)=x, \quad F(y, x)=g(y)=y .
$$

Definition 1.12 Let $F: X \times X \rightarrow X$ and $g: X \rightarrow X$ be mappings. The mappings $F$ and $g$ are said to commute if

$$
g(F(x, y))=F(g(x), g(y)), \quad \text { for all } x, y \in X .
$$

Definition 1.13 (See [4]) Let $(X, \leq)$ be a partially ordered set and $F: X \times X \rightarrow X$ be a mapping. Then $F$ is said to have mixed monotone property if $F(x, y)$ is monotone nondecreasing in $x$ and is monotone non-increasing in $y$, that is, for any $x, y \in X$,

$$
x_{1} \leq x_{2} \quad \Rightarrow \quad F\left(x_{1}, y\right) \leq F\left(x_{2}, y\right), \quad \text { for } x_{1}, x_{2} \in X \text {, }
$$

and

$$
y_{1} \leq y_{2} \quad \Rightarrow \quad F\left(x, y_{2}\right) \leq F\left(x, y_{1}\right), \quad \text { for } y_{1}, y_{2} \in X .
$$

Definition 1.14 (See [5]) Let $(X, \leq)$ be a partially ordered set and $F: X \times X \rightarrow X$ and $g: X \rightarrow X$ be two mappings. Then $F$ is said to have mixed $g$-monotone property if $F(x, y)$ is monotone $g$-non-decreasing in $x$ and is monotone $g$-non-increasing in $y$, that is, for any $x, y \in X$,

$$
g\left(x_{1}\right) \leq g\left(x_{2}\right) \quad \Rightarrow \quad F\left(x_{1}, y\right) \leq F\left(x_{2}, y\right), \quad \text { for } x_{1}, x_{2} \in X,
$$

and

$$
g\left(y_{1}\right) \leq g\left(y_{2}\right) \quad \Rightarrow \quad F\left(x, y_{2}\right) \leq F\left(x, y_{1}\right), \quad \text { for } y_{1}, y_{2} \in X
$$

Let $\Phi$ denote the set of functions $\phi:[0, \infty) \rightarrow[0, \infty)$ satisfying

(a) $\phi^{-1}(\{0\})=\{0\}$,

(b) $\phi(t)<t$ for all $t>0$,

(c) $\lim _{r \rightarrow t^{+}} \phi(r)<t$ for all $t>0$.

Lemma 1.15 (See [5]) Let $\phi \in \Phi$. For all $t>0$, we have $\lim _{n \rightarrow \infty} \phi^{n}(t)=0$. 
Aydi et al. [1] proved the following theorems.

Theorem 1.16 Let $(X, \preceq)$ be a partially ordered set and $G$ be a G-metric on $X$ such that $(X, G)$ is a complete G-metric space. Suppose that there exist $\phi \in \Phi, F: X \times X \rightarrow X$ and $g: X \rightarrow X$ such that

$$
G(F(x, y), F(u, v), F(w, z)) \leq \phi\left(\frac{G(g x, g u, g w)+G(g y, g v, g z)}{2}\right)
$$

for all $x, y, u, v, w, z \in X$ with $g w \preceq g u \preceq g x$ and $g y \preceq g v \preceq g z$. Suppose also that $F$ is continuous and has the mixed $g$-monotone property, $F(X \times X) \subseteq g(X)$ and $g$ is continuous and commutes with $F$. If there exist $x_{0}, y_{0} \in X$ such that $g x_{0} \preceq F\left(x_{0}, y_{0}\right)$ and $F\left(y_{0}, x_{0}\right) \preceq g y_{0}$, then $F$ and $g$ have a coupled coincidence point, that is, there exists $(x, y) \in X \times X$ such that $g x=F(x, y)$ and $g y=F(y, x)$.

Theorem 1.17 Let $(X, \preceq)$ be a partially ordered set and $G$ be a G-metric on $X$ such that $(X, G, \preceq)$ is regular. Suppose that there exist $\phi \in \Phi$ and mappings $F: X \times X \rightarrow X$ and $g: X \rightarrow X$ such that

$$
G(F(x, y), F(u, v), F(w, z)) \leq \phi\left(\frac{G(g x, g u, g w)+G(g y, g v, g z)}{2}\right)
$$

for all $x, y, u, v, w, z \in X$ with $g w \preceq g u \preceq g x$ and $g y \preceq g v \preceq g z$. Suppose also that $(g(X), G)$ is complete, $F$ has the mixed $g$-monotone property and $F(X \times X) \subseteq g(X)$. If there exist $x_{0}, y_{0} \in$ $X$ such that $g x_{0} \preceq F\left(x_{0}, y_{0}\right)$ and $F\left(y_{0}, x_{0}\right) \preceq$ gy $y_{0}$, then $F$ and $g$ have a coupled coincidence point.

In this manuscript, we generalize, improve, enrich and extend the above coupled fixed point results. We also state some examples to illustrate our results. This paper can be considered as a continuation of the remarkable works of Berinde [6, 7].

\section{Main results}

We begin with an example to illustrate the weakness of Theorem 1.16 and Theorem 1.17 above.

Example 2.1 Let $X=\mathbb{R}$. Define $G: X \times X \times X \rightarrow[0, \infty)$ by

$$
G(x, y, z)=|x-y|+|x-z|+|y-z|
$$

for all $x, y, z \in X$. Then $(X, G)$ is a $G$-metric space. Define a map $F: X \times X \rightarrow X$ by $F(x, y)=$ $\frac{1}{12} x+\frac{7}{12} y$ and $g: X \rightarrow X$ by $g(x)=\frac{x}{2}$ for all $x, y \in X$. Suppose $x=u=z$

$$
\begin{aligned}
& G(F(x, y), F(u, v), F(z, w)) \\
& \quad=G\left(\frac{1}{12} x+\frac{7}{12} y, \frac{1}{12} u+\frac{7}{12} v, \frac{1}{12} z+\frac{7}{12} w\right) \\
& \quad=\frac{7}{12}|v-y|+\frac{7}{12}|w-y|+\frac{7}{12}|w-v|
\end{aligned}
$$


and

$$
\begin{aligned}
G(g x, g u, g z)+G(g y, g v, g w) & =G\left(\frac{x}{2}, \frac{u}{2}, \frac{z}{2}\right)+G\left(\frac{y}{2}, \frac{v}{2}, \frac{w}{2}\right) \\
& =\frac{1}{2}[|y-v|+|y-w|+|v-w|] .
\end{aligned}
$$

It is clear that there is no $\phi \in \Phi$ that provides the statement (1.4) of Theorem 1.16.

Notice that $(0,0)$ is the unique common coincidence point of $F$ and $g$. In fact, $F(0,0)=$ $g(0)=0$.

For some coupled fixed point and coupled coincidence point theorems, we refer the reader to [8-34].

We now state our first result which successively guarantees a coupled fixed point.

Theorem 2.2 Let $(X, \preceq)$ be a partially ordered set and $G$ be a G-metric on $X$ such that $(X, G)$ is a complete $G$-metric space. Suppose that there exist $\phi \in \Phi, F: X \times X \rightarrow X$ and $g: X \rightarrow X$ such that

$$
\begin{aligned}
& {[G(F(x, y), F(u, v), F(w, z))+G(F(y, x), F(v, u), F(z, w))]} \\
& \quad \leq \phi(G(g x, g u, g w)+G(g y, g v, g z))
\end{aligned}
$$

for all $x, y, u, v, w, z \in X$ with $g w \preceq g u \preceq g x$ and $g y \preceq g v \preceq g z$. Suppose also that $F$ is continuous and has the mixed $g$-monotone property, $F(X \times X) \subseteq g(X)$ and $g$ is continuous and commutes with $F$. If there exist $x_{0}, y_{0} \in X$ such that $g x_{0} \preceq F\left(x_{0}, y_{0}\right)$ and $F\left(y_{0}, x_{0}\right) \preceq g y_{0}$, then $F$ and $g$ have a coupled coincidence point, that is, there exists $(x, y) \in X \times X$ such that $g x=F(x, y)$ and $g y=F(y, x)$.

Proof Given $x_{0}, y_{0} \in X$ satisfying $g x_{0} \preceq F\left(x_{0}, y_{0}\right)$ and $F\left(y_{0}, x_{0}\right) \preceq g y_{0}$, we shall construct iterative sequences $\left(x_{n}\right)$ and $\left(y_{n}\right)$ in the following way: Since $F(X \times X) \subseteq g(X)$, we can choose $x_{1}, y_{1} \in X$ such that $g x_{1}=F\left(x_{0}, y_{0}\right)$ and $g y_{1}=F\left(y_{0}, x_{0}\right)$. Analogously, we choose $x_{2}, y_{2} \in X$ such that $g x_{2}=F\left(x_{1}, y_{1}\right)$ and $g y_{2}=F\left(y_{1}, x_{1}\right)$ due to the same reasoning. Since $F$ has the mixed $g$-monotone property, we conclude that $g x_{0} \preceq g x_{1} \preceq g x_{2}$ and $g y_{2} \preceq g y_{1} \preceq g y_{0}$. By repeating this process, we derive the iterative sequence

$$
g x_{n}=F\left(x_{n-1}, y_{n-1}\right) \preceq g x_{n+1}=F\left(x_{n}, y_{n}\right)
$$

and

$$
g y_{n+1}=F\left(y_{n}, x_{n}\right) \preceq g y_{n}=F\left(y_{n-1}, x_{n-1}\right) .
$$

If for some $n_{0}$ we have $\left(g x_{n_{0}+1}, g y_{n_{0}+1}\right)=\left(g x_{n_{0}}, g y_{n_{0}}\right)$, then $F\left(x_{n_{0}}, y_{n_{0}}\right)=g x_{n_{0}}$ and $F=$ $\left(y_{n_{0}}, x_{n_{0}}\right)=g y_{n_{0}}$, that is, $F$ and $g$ have a coincidence point. So, we assume that $\left(g x_{n+1}, g y_{n+1}\right) \neq$ $\left(g x_{n}, g y_{n}\right)$ for all $n \in \mathbb{N}$. Thus, we have either $g x_{n+1}=F\left(x_{n}, y_{n}\right) \neq g x_{n}$ or $g y_{n+1}=F\left(y_{n}, x_{n}\right) \neq g y_{n}$. We set

$$
t_{n}=G\left(g x_{n+1}, g x_{n+1}, g x_{n}\right)+G\left(g y_{n+1}, g y_{n+1}, g y_{n}\right)
$$


for all $n \in \mathbb{N}$. Due to the property (G2), we have $t_{n}>0$ for all $n \in \mathbb{N}$. By using inequality (2.3), we obtain

$$
\begin{aligned}
& G\left(g x_{n+1}, g x_{n+1}, g x_{n}\right)+G\left(g y_{n+1}, g y_{n+1}, g y_{n}\right) \\
& =G\left(F\left(x_{n}, y_{n}\right), F\left(x_{n}, y_{n}\right), F\left(g x_{n-1}, g y_{n-1}\right)\right) \\
& \quad+G\left(F\left(y_{n}, x_{n}\right), F\left(y_{n}, x_{n}\right), F\left(g y_{n-1}, g x_{n-1}\right)\right) \\
& \leq \phi\left(G\left(g x_{n}, g x_{n}, g x_{n-1}\right)+G\left(g y_{n}, g y_{n}, g y_{n-1}\right)\right) .
\end{aligned}
$$

Taking (2.4) into account, (2.5) becomes

$$
t_{n} \leq \phi\left(t_{n-1}\right)
$$

Since $\phi(t)<t$ for all $t>0$, it follows that $t_{n}$ is monotone decreasing. Therefore, there is some $L \geq 0$ such that $\lim _{n \rightarrow+\infty} t_{n}=L$.

Now, we assert that $L=0$. Suppose, on the contrary, that $L>0$. Letting $n \rightarrow+\infty$ in (2.6) and using the properties of the map $\phi$, we get

$$
L=\lim _{n \rightarrow+\infty} t_{n} \leq \lim _{n \rightarrow+\infty} \phi\left(t_{n-1}\right)<L
$$

which is contradiction. Thus $L=0$. Hence

$$
\lim _{n \rightarrow+\infty} t_{n}=\lim _{n \rightarrow+\infty} G\left(g x_{n+1}, g x_{n+1}, g x_{n}\right)+G\left(g y_{n}, g y_{n}, g y_{n-1}\right)=0
$$

Next, we prove that $\left(g x_{n}\right)$ and $\left(g y_{n}\right)$ are Cauchy sequences in the $G$-metric space $(X, G)$. Suppose, on the contrary, that at least one of $\left(g x_{n}\right)$ and $\left(g y_{n}\right)$ is not a Cauchy sequence in $(X, G)$. Then there exist $\varepsilon>0$ and sequences of natural numbers $(m(k))$ and $(l(k))$ such that for every natural number $k, m(k)>l(k) \geq k$ and

$$
r_{k}=G\left(g x_{m(k)}, g x_{m(k)}, g x_{l(k)}\right)+G\left(g y_{m(k)}, g y_{m(k)}, g y_{l(k)}\right) \geq \varepsilon .
$$

Now, corresponding to $l(k)$, we choose $m(k)$ to be the smallest for which (2.8) holds. Hence

$$
G\left(g x_{m(k)-1}, g x_{m(k)-1}, g x_{l(k)}\right)+G\left(g y_{m(k)-1}, g y_{m(k)-1}, g y_{l(k)}\right)<\varepsilon
$$

Using the rectangle inequality (property (G5)), we get

$$
\begin{aligned}
\varepsilon \leq & r_{k} \\
\leq & G\left(g x_{m(k)}, g x_{m(k)}, g x_{m(k)-1}\right)+G\left(g x_{m(k)-1}, g x_{m(k)-1}, g x_{l(k)}\right) \\
& +G\left(g y_{m(k)}, g y_{m(k)}, g y_{m(k)-1}\right)+G\left(g y_{m(k)-1}, g y_{m(k)-1}, g y_{l(k)}\right) \\
= & G\left(g x_{m(k)-1}, g x_{m(k)-1}, g x_{l(k)}\right)+G\left(g y_{m(k)-1}, g y_{m(k)-1}, g y_{l(k)}\right)+t_{m(k)-1} \\
< & \varepsilon+t_{m(k)-1} .
\end{aligned}
$$

Letting $k \rightarrow+\infty$ in the above inequality and using (2.7) yields

$$
\lim _{k \rightarrow+\infty} r_{k}=\varepsilon^{+}
$$


Again, by the rectangle inequality, we have

$$
\begin{aligned}
r_{k}= & G\left(g x_{m(k)}, g x_{m(k)}, g x_{l(k)}\right)+G\left(g y_{m(k)}, g y_{m(k)}, g y_{l(k)}\right) \\
\leq & G\left(g x_{m(k)}, g x_{m(k)}, g x_{m(k)+1}\right)+G\left(g x_{m(k)+1}, g x_{m(k)+1}, g x_{l(k)+1}\right) \\
& +G\left(g x_{l(k)+1}, g x_{l(k)+1}, g x_{l(k)}\right)+G\left(g y_{m(k)}, g y_{m(k)}, g y_{m(k)+1}\right) \\
& +G\left(g y_{m(k)+1}, g y_{m(k)+1}, g y_{l(k)+1}\right)+G\left(g y_{l(k)+1}, g y_{l(k)+1}, g y_{l(k)}\right) \\
= & t_{l(k)}+G\left(g x_{m(k)}, g x_{m(k)}, g x_{m(k)+1}\right)+G\left(g y_{m(k)}, g y_{m(k)}, g y_{m(k)+1}\right) \\
& +G\left(g x_{m(k)+1}, g x_{m(k)+1}, g x_{l(k)+1}\right)+G\left(g y_{m(k)+1}, g y_{m(k)+1}, g y_{l(k)+1}\right) .
\end{aligned}
$$

Using the fact that $G(x, x, y) \leq 2 G(x, y, y)$ for any $x, y \in X$, we obtain from properties (G2)(G4)

$$
\begin{aligned}
r_{k} \leq & t_{l(k)}+2 G\left(g x_{m(k)}, g x_{m(k)}, g x_{m(k)+1}\right)+2 G\left(g y_{m(k)}, g y_{m(k)}, g y_{m(k)+1}\right) \\
& +G\left(g x_{m(k)+1}, g x_{m(k)+1}, g x_{l(k)+1}\right)+G\left(g y_{m(k)+1}, g y_{m(k)+1}, g y_{l(k)+1}\right) \\
= & t_{l(k)}+2 t_{m(k)}+G\left(g x_{m(k)+1}, g x_{m(k)+1}, g x_{l(k)+1}\right)+G\left(g y_{m(k)+1}, g y_{m(k)+1}, g y_{l(k)+1}\right) .
\end{aligned}
$$

Next, using inequality (2.3), we have

$$
\begin{aligned}
& G(\left.g x_{m(k)+1}, g x_{m(k)+1}, g x_{l(k)+1}\right)+G\left(g y_{m(k)+1}, g y_{m(k)+1}, g y_{l(k)+1}\right) \\
&= G\left(F\left(x_{m(k)}, y_{m(k)}\right), F\left(x_{m(k)}, y_{m(k)}\right), F\left(x_{l(k)}, y_{l(k)}\right)\right) \\
& \quad+G\left(F\left(y_{l(k)}, x_{l(k)}\right), F\left(y_{m(k)}, x_{m(k)}\right), F\left(y_{m(k)}, x_{m(k)}\right)\right) \\
& \leq \phi\left(G\left(g x_{m(k)}, g x_{m(k)}, g x_{l(k)}\right)+G\left(g y_{m(k)}, g y_{m(k)}, g y_{l(k)}\right)\right) \\
& \leq \phi\left(r_{k}\right) .
\end{aligned}
$$

Now, using (2.7),(2.10), the properties of the function $\phi$, and letting $k \rightarrow+\infty$ in (2.11), we get

$$
\varepsilon \leq \lim _{k \rightarrow+\infty} \phi\left(r_{k}\right)=\lim _{t \rightarrow(\varepsilon)^{+}} \phi(t)<\varepsilon,
$$

which is a contradiction. Thus, we have proven that $\left(g x_{n}\right)$ and $\left(g y_{n}\right)$ are Cauchy sequences in the $G$-metric space $(X, G)$. Now, since $(X, G)$ is complete, there are $x, y \in X$ such that $\left(g x_{n}\right)$ and $\left(g y_{n}\right)$ are respectively G-convergent to $x$ and $y$. That is from Proposition 1.4, we have

$$
\begin{aligned}
& \lim _{n \rightarrow+\infty} G\left(g x_{n}, g x_{n}, x\right)=\lim _{n \rightarrow+\infty} G\left(g x_{n}, x, x\right)=0, \\
& \lim _{n \rightarrow+\infty} G\left(g y_{n}, g y_{n}, y\right)=\lim _{n \rightarrow+\infty} G\left(g y_{n}, y, y\right)=0 .
\end{aligned}
$$

Using the continuity of $g$, we get from Proposition 1.7

$$
\begin{aligned}
& \lim _{n \rightarrow+\infty} G\left(g\left(g x_{n}\right), g\left(g x_{n}\right), g x\right)=\lim _{n \rightarrow+\infty} G\left(g\left(g x_{n}\right), g x, g x\right)=0, \\
& \lim _{n \rightarrow+\infty} G\left(g\left(g y_{n}\right), g\left(g y_{n}\right), g y\right)=\lim _{n \rightarrow+\infty} G\left(g\left(g y_{n}\right), g y, g y\right)=0 .
\end{aligned}
$$


Since $g x_{n+1}=F\left(x_{n}, y_{n}\right)$ and $g y_{n+1}=F\left(y_{n}, x_{n}\right)$, employing the commutativity of $F$ and $g$ yields

$$
\begin{aligned}
& g\left(g x_{n+1}\right)=g\left(F\left(x_{n}, y_{n}\right)\right)=F\left(g x_{n}, g y_{n}\right), \\
& g\left(g y_{n+1}\right)=g\left(F\left(y_{n}, x_{n}\right)\right)=F\left(g y_{n}, g x_{n}\right) .
\end{aligned}
$$

Now, we shall show that $F(x, y)=g x$ and $F(y, x)=g y$.

The mapping $F$ is continuous, and since the sequences $\left(g x_{n}\right)$ and $\left(g y_{n}\right)$ are respectively G-convergent to $x$ and $y$, using Definition 1.9, the sequence $\left(F\left(g x_{n}, g y_{n}\right)\right)$ is $G$-convergent to $F(x, y)$. Therefore, from (2.13), $\left(g\left(g x_{n+1}\right)\right)$ is $G$-convergent to $F(x, y)$. By uniqueness of the limit and using (2.12), we have $F(x, y)=g x$. Similarly, we can show that $F(y, x)=g y$. Hence, $(x, y)$ is a coupled coincidence point of $F$ and $g$. This completes the proof.

The following example illustrates that Theorem 2.2 is an extension of Theorem 1.16.

Example 2.3 Let us reconsider Example 2.1. Define a map $F: X \times X \rightarrow X$ by

$$
F(x, y)=\frac{1}{12} x+\frac{7}{12} y
$$

and $g: X \rightarrow X$ by $g(x)=\frac{x}{2}$ for all $x, y \in X$. Then $F(X \times X)=[0, \infty)=g(X)=X$. We observe that

$$
\begin{aligned}
G( & (x, y), F(u, v), F(z, w))+G(F(y, x), F(v, u), F(w, z)) \\
= & G\left(\frac{1}{12} x+\frac{7}{12} y, \frac{1}{12} u+\frac{7}{12} v, \frac{1}{12} z+\frac{7}{12} w\right) \\
& +G\left(\frac{1}{12} y+\frac{7}{12} x, \frac{1}{12} v+\frac{7}{12} u, \frac{1}{12} w+\frac{7}{12} z\right) \\
= & \frac{7}{12}|v-y|+\frac{7}{12}|w-y|+\frac{7}{12}|w-v| \\
& +\frac{1}{12}|u-x|+\frac{1}{12}|z-x|+\frac{1}{12}|z-u| \\
& +\frac{1}{12}|v-y|+\frac{1}{12}|w-y|+\frac{1}{12}|w-v| \\
& +\frac{7}{12}|u-x|+\frac{7}{12}|z-x|+\frac{7}{12}|z-u| \\
= & \frac{8}{12}(|v-y|+|w-y|+|w-v|) \\
& +\frac{8}{12}(|u-x|+|z-x|+|z-u|)
\end{aligned}
$$

and

$$
\begin{aligned}
G(g x, g u, g z)+G(g y, g v, g w)= & G\left(\frac{1}{2} x, \frac{1}{2} u, \frac{1}{2} z\right)+G\left(\frac{1}{2} y, \frac{1}{2} v, \frac{1}{2} w\right) \\
= & \frac{1}{2}[(|x-u|+|x-z|+|u-z|) \\
& +(|y-v|+|y-w|+|v-w|)] .
\end{aligned}
$$


Then, the statement (2.3) of Theorem 2.2 is satisfied for $\phi(t)=\frac{2}{3} t$ and $(0,0)$ is the desired coupled coincidence point.

In the next theorem, we omit the continuity hypothesis of $F$.

Theorem 2.4 Let $(X, \preceq)$ be a partially ordered set and $G$ be a G-metric on $X$ such that $(X, G, \preceq)$ is $g$-ordered complete. Suppose that there exist $\phi \in \Phi$ and mappings $F: X \times X \rightarrow$ $X$ and $g: X \rightarrow X$ such that

$$
\begin{aligned}
& {[G(F(x, y), F(u, v), F(w, z))+G(F(y, x), F(v, u), F(z, w))]} \\
& \quad \leq \phi(G(g x, g u, g w)+G(g y, g v, g z))
\end{aligned}
$$

for all $x, y, u, v, w, z \in X$ with $g w \preceq g u \preceq g x$ and $g y \preceq g v \preceq g z$. Suppose also that $(g(X), G)$ is complete, $F$ has the mixed $g$-monotone property and $F(X \times X) \subseteq g(X)$. If there exist $x_{0}, y_{0} \in$ $X$ such that $g x_{0} \preceq F\left(x_{0}, y_{0}\right)$ and $F\left(y_{0}, x_{0}\right) \preceq g y_{0}$, then $F$ and $g$ have a coupled coincidence point.

Proof Proceeding exactly as in Theorem 2.2, we have that $\left(g x_{n}\right)$ and $\left(g y_{n}\right)$ are Cauchy sequences in the complete $G$-metric space $(g(X), G)$. Then, there exist $x, y \in X$ such that $g x_{n} \rightarrow g x$ and $g y_{n} \rightarrow g y$. Since $\left(g x_{n}\right)$ is non-decreasing and $\left(g y_{n}\right)$ is non-increasing, using the regularity of $(X, G, \preceq)$, we have $g x_{n} \preceq g x$ and $g y \preceq g y_{n}$ for all $n \geq 0$. If $g x_{n}=g x$ and $g y_{n}=g y$ for some $n \geq 0$, then $g x=g x_{n} \preceq g x_{n+1} \preceq g x=g x_{n}$ and $g y \preceq g y_{n+1} \preceq g y_{n}=g y$, which implies that $g x_{n}=g x_{n+1}=F\left(x_{n}, y_{n}\right)$ and $g y_{n}=g y_{n+1}=F\left(y_{n}, x_{n}\right)$, that is, $\left(x_{n}, y_{n}\right)$ is a coupled coincidence point of $F$ and $g$. Then, we suppose that $\left(g x_{n}, g y_{n}\right) \neq(g x, g y)$ for all $n \geq 0$. Using the rectangle inequality, (2.15) and property $\phi(t)<t$ for all $t>0$, we get

$$
\begin{aligned}
G( & F(x, y), g x, g x)+G(F(y, x), g y, g y) \\
\leq & G\left(F(x, y), g x_{n+1}, g x_{n+1}\right)+G\left(g x_{n+1}, g x, g x\right) \\
& +G\left(F(y, x), g y_{n+1}, g y_{n+1}\right)+G\left(g y_{n+1}, g y, g y\right) \\
= & G\left(F(x, y), F\left(x_{n}, y_{n}\right), F\left(x_{n}, y_{n}\right)\right)+G\left(g x_{n+1}, g x, g x\right) \\
\quad & +G\left(F(y, x), F\left(y_{n}, x_{n}\right), F\left(y_{n}, x_{n}\right)\right)+G\left(g y_{n+1}, g y, g y\right) \\
\leq & \phi\left(G\left(g x, g x_{n}, g x_{n}\right)+G\left(g y, g y_{n}, g y_{n}\right)\right) \\
& +G\left(g x_{n+1}, g x, g x\right)+G\left(g y_{n+1}, g y, g y\right) \\
< & G\left(g x, g x_{n}, g x_{n}\right)+G\left(g y, g y_{n}, g y_{n}\right) \\
& +G\left(g x_{n+1}, g x, g x\right)+G\left(g y_{n+1}, g y, g y\right) .
\end{aligned}
$$

Letting $n \rightarrow+\infty$ in the above inequality, we obtain

$$
G(F(x, y), g x, g x)+G(F(y, x), g y, g y)=0
$$

which implies that $g x=F(x, y)$ and $g y=F(y, x)$. Thus we proved that $(x, y)$ is a coupled coincidence point of $F$ and $g$. 
Corollary 2.5 Let $(X, \preceq)$ be a partially ordered set and $G$ be a G-metric on $X$ such that $(X, G)$ is a complete $G$-metric space. Suppose that there exist $k \in[0,1), F: X \times X \rightarrow X$ and $g: X \rightarrow X$ such that

$$
\begin{aligned}
& {[G(F(x, y), F(u, v), F(w, z))+G(F(y, x), F(v, u), F(z, w))]} \\
& \quad \leq k[G(g x, g u, g w)+G(g y, g v, g z)]
\end{aligned}
$$

for all $x, y, u, v, w, z \in X$ with $g w \preceq g u \preceq g x$ and $g y \preceq g v \preceq g z$. Suppose also that $F$ is continuous, has the mixed g-monotone property, $F(X \times X) \subseteq g(X)$ and $g$ is continuous and commutes with $F$. If there exist $x_{0}, y_{0} \in X$ such that $g x_{0} \preceq F\left(x_{0}, y_{0}\right)$ and $F\left(y_{0}, x_{0}\right) \preceq g y_{0}$, then $F$ and $g$ have a coupled coincidence point.

Proof Taking $\phi(t)=k t$ with $k \in[0,1)$ in Theorem 2.4, we obtain Corollary 2.5.

Corollary 2.6 Let $(X, \preceq)$ be a partially ordered set and $G$ be a G-metric on $X$ such that $(X, G, \preceq)$ is g-ordered complete. Suppose that there exist $k \in[0,1), F: X \times X \rightarrow X$ and $g: X \rightarrow X$ such that

$$
\begin{aligned}
& {[G(F(x, y), F(u, v), F(w, z))+G(F(y, x), F(v, u), F(z, w))]} \\
& \quad \leq k[G(g x, g u, g w)+G(g y, g v, g z)]
\end{aligned}
$$

for all $x, y, u, v, w, z \in X$ with $g w \preceq g u \preceq g x$ and $g y \preceq g v \preceq g z$. Suppose also that $(g(X), G)$ is complete, $F$ has the mixed $g$-monotone property, $F(X \times X) \subseteq g(X)$. If there exist $x_{0}, y_{0} \in X$ such that $g x_{0} \preceq F\left(x_{0}, y_{0}\right)$ and $F\left(y_{0}, x_{0}\right) \preceq g y_{0}$, then $F$ and $g$ have a coupled coincidence point.

Proof Taking $\phi(t)=k t$ with $k \in[0,1)$ in Theorem 2.4, we obtain Corollary 2.6

Remark 2.7 Taking $g=l_{x}$ (the identity mapping) in Corollary 2.5, we obtain [2, Theorem 3.1]. Taking $g=I_{x}$ in Corollary 2.6, we obtain [2, Theorem 3.2].

Now we shall prove the existence and uniqueness theorem of a coupled common fixed point. If $(X, \preceq)$ is a partially ordered set, we endow the product set $X \times X$ with the partial order $\nabla$ defined by

$$
(x, y) \nabla(u, v) \quad \Longleftrightarrow \quad x \preceq u, \quad v \preceq y .
$$

Theorem 2.8 In addition to the hypothesis of Theorem 2.2, suppose that for all $(x, y)$, $\left(x^{*}, y^{*}\right) \in(X \times X)$, there exists $(u, v) \in X \times X$ such that $(F(x, y), F(u, v))$ is comparable with $(F(x, y), F(y, x))$ and $\left(F\left(x^{*}, y^{*}\right), F\left(y^{*}, x^{*}\right)\right)$. Suppose also that $\phi$ is a non-decreasing function. Then $F$ and $g$ have a unique coupled common fixed point, that is, there exists a unique $(x, y) \in X \times X$ such that

$$
x=g x=F(x, y) \text { and } y=g y=F(y, x) .
$$

Proof From Theorem 2.2, the set of coupled coincidences is non-empty. We shall show that if $(x, y)$ and $\left(x^{*}, y^{*}\right)$ are coupled coincidence points, that is, if $g x=F(x, y), g(y)=F(y, x)$, 
$g x^{*}=F\left(x^{*}, y^{*}\right)$ and $g y^{*}=F\left(y^{*}, x^{*}\right)$, then

$$
g x=g x^{*} \text { and } g y=g y^{*} .
$$

By assumption, there exists $(u, v) \in X \times X$ such that $(F(u, v), F(v, u))$ is comparable with $(F(x, y), F(y, x))$ and $\left(F\left(x^{*}, y^{*}\right), F\left(y^{*}, x^{*}\right)\right)$. Without loss of generality, we can assume that

$$
(F(x, y), F(y, x)) \nabla(F(u, v), F(v, u))
$$

and

$$
\left(F\left(x^{*}, y^{*}\right), F\left(y^{*}, x^{*}\right)\right) \nabla(F(u, v), F(v, u)) \text {. }
$$

Put $u_{0}=u, v_{0}=v$ and choose $u_{1}, v_{1} \in X$ such that $g u_{1}=F\left(u_{0}, v_{0}\right)$ and $g v_{1}=F\left(v_{0}, u_{0}\right)$. Then, similarly as in the proof of Theorem 2.2 , we can inductively define sequences $\left(g u_{n}\right)$ and $\left(g v_{n}\right)$ in $X$ by $g u_{n+1}=F\left(u_{n}, v_{n}\right)$ and $g v_{n+1}=F\left(v_{n}, u_{n}\right)$.

Further, set $x_{0}=x, y_{0}=y, x_{0}{ }^{*}=x^{*}, y_{0}{ }^{*}=y^{*}$ and, in the same way, define the sequences $\left(g x_{n}\right),\left(g y_{n}\right),\left(g x_{n}{ }^{*}\right)$ and $\left(g y_{n}{ }^{*}\right)$. Since

$$
(F(x, y), F(y, x))=\left(g x_{1}, g y_{1}\right)=(g x, g y) \nabla(F(u, v), F(v, u))=\left(g u_{1}, g v_{1}\right),
$$

then $g x \preceq g u_{1}$ and $g v_{1} \preceq g y$. Using that $F$ is a mixed $g$-monotone mapping, one can show easily that $g x \preceq g u_{n}$ and $g v_{n} \preceq g y$ for all $n \geq 1$. Thus from (2.15), we get

$$
\begin{aligned}
G\left(g u_{n+1}, g x, g x\right)+G\left(g y, g y, g v_{n+1}\right)= & G\left(F\left(u_{n}, v_{n}\right), F(x, y), F(x, y)\right) \\
& +G\left(F(y, x), F(y, x), F\left(v_{n}, u_{n}\right)\right) \\
\leq & \phi\left(G\left(g u_{n}, g x, g x\right)+G\left(g v_{n}, g y, g y\right)\right) .
\end{aligned}
$$

Without loss of generality, we can suppose that $\left(g u_{n}, g v_{n}\right) \neq(g x, g y)$ for all $n \geq 1$. Since $\phi$ is non-decreasing, from the previous inequality, we get

$$
G\left(g u_{n+1}, g x, g x\right)+G\left(g v_{n+1}, g y, g y\right) \leq \phi^{n}\left(G\left(g u_{1}, g x, g x\right)+G\left(g v_{1}, g y, g y\right)\right)
$$

for each $n \geq 1$. Letting $n \rightarrow+\infty$ in the above inequality and using Lemma 1.15 , we obtain

$$
\lim _{n \rightarrow+\infty} G\left(g u_{n+1}, g x, g x\right)=0 \text { and } \lim _{n \rightarrow+\infty} G\left(g v_{n+1}, g y, g y\right)=0 .
$$

Analogously, we derive that

$$
\lim _{n \rightarrow+\infty} G\left(g u_{n+1}, g x^{*}, g x^{*}\right)=0 \text { and } \lim _{n \rightarrow+\infty} G\left(g v_{n+1}, g y^{*}, g y^{*}\right)=0
$$

Hence, from (2.17), (2.18) and the uniqueness of the limit, we get $g x=g x^{*}$ and $g y=g y^{*}$. Hence the equalities in (2.16) are satisfied. Since $g x=F(x, y)$ and $g y=F(y, x)$, by commutativity of $F$ and $g$, we have

$$
g(g x)=g(F(x, y))=F(g x, g y) \text { and } \quad g(g y)=g(F(y, x))=F(g y, g x) .
$$


Denote $g x=z$ and $g y=w$, then by (2.19), we get

$$
g z=F(z, w) \text { and } g w=F(w, z) .
$$

Thus, $(z, w)$ is a coincidence point. Then, from (2.16) with $x^{*}=z$ and $y^{*}=w$, we have $g x=g z$ and $g y=g w$, that is,

$$
g z=z \text { and } g w=w .
$$

From (2.20), (2.21), we get

$$
z=g z=F(z, w) \quad \text { and } \quad w=g w=F(w, z) .
$$

Then, $(z, w)$ is a coupled common fixed point of $F$ and $g$.

To prove the uniqueness, assume that $(p, q)$ is another coupled common fixed point. Then by (2.16), we have $p=g p=g z=z$ and $q=g q=g w=w$.

Theorem 2.9 Let $(X, \preceq)$ be a partially ordered set and $G$ be a G-metric on $X$ such that $(X, G)$ is a complete $G$-metric space and $(X, G, \preceq)$ is regular. Suppose that there exist $\phi \in \Phi$ and $F: X \times X \rightarrow X$ having the mixed monotone property such that

$$
G(F(x, y), F(u, v), F(w, z))+G(F(y, x), F(v, u), F(z, w)) \leq \phi(G(x, u, w)+G(y, v, z)),
$$

for all $x, y, u, v, w, z \in X$ with $w \preceq u \preceq x$ and $y \preceq v \preceq z$. If there exist $x_{0}, y_{0} \in X$ such that $x_{0} \preceq F\left(x_{0}, y_{0}\right)$ and $F\left(y_{0}, x_{0}\right) \preceq y_{0}$, then $F$ has a coupled fixed point. Furthermore, if $y_{0} \preceq x_{0}$, then $x=y$, that is, $x=F(x, x)$.

Proof Following the proof of Theorem 2.4 with $g=I_{x}$, we have only to show that $x=F(x, x)$. Since $y_{0} \preceq x_{0}$, we get $y \preceq y_{n} \preceq \cdots \preceq y_{1} \preceq y_{0} \preceq x_{0} \preceq x_{1} \preceq \cdots \preceq x_{n} \preceq x$.

Thus, we have $y \preceq x$. Suppose that $G(x, x, y)>0$. Using inequality (2.15), we have

$$
\begin{aligned}
G(x, x, y)+G(x, y, y) & =G(F(x, y), F(x, y), F(y, x))+G(F(x, y), F(y, x), F(y, x)) \\
& \leq \phi(G(x, x, y)+G(y, y, x)) \\
& <G(x, x, y)+G(x, y, y),
\end{aligned}
$$

a contradiction. Thus, $G(x, x, y)=0$ and $x=y=F(x, x)$.

Competing interests

The authors declare that they have no competing interests.

Authors' contributions

All authors have contributed equally. All authors read and approved the final manuscript.

\section{Author details}

'Department of Mathematics, Atlım University, Incek, Ankara 06836, Turkey. ${ }^{2}$ Department of Mathematics and

Computer Science, Çankaya University, Ankara, Turkey. 


\section{References}

1. Aydi, H, Damjanović, B, Samet, B, Shatanawi, W: Coupled fixed point theorems for nonlinear contractions in partially ordered G-metric spaces. Math. Comput. Model. 54, 2443-2450 (2011)

2. Choudhury, BS, Maity, P: Coupled fixed point results in generalized metric spaces. Math. Comput. Model. 54(1-2), 73-79 (2011)

3. Mustafa, Z, Sims, B: A new approach to generalized metric spaces. J. Nonlinear Convex Anal. 7(2), $289-297$ (2006)

4. Gnana-Bhaskar, T, Lakshmikantham, V: Fixed point theorems in partially ordered metric spaces and applications. Nonlinear Anal. 65, 1379-1393 (2006)

5. Ćirić, L, Lakshmikantham, V: Coupled fixed point theorems for nonlinear contractions in partially ordered metric spaces. Nonlinear Anal. 70, 4341-4349 (2009)

6. Berinde, V: Generalized coupled fixed point theorems for mixed monotone mappings in partially ordered metric spaces. Nonlinear Anal. 74, 7347-7355 (2011)

7. Berinde, V: Coupled coincidence point theorems for mixed monotone nonlinear operators. Comput. Math. Appl. (2012). doi:10.1016/j.camwa.2012.02.012

8. Abbas, M, Sintunavarat, W, Kumam, P: Coupled fixed point of generalized contractive mappings on partially ordered G-metric spaces. Fixed Point Theory Appl. 2012, 31 (2012)

9. Aydi, $H$, Postolache, $M$, Shatanawi, W: Coupled fixed point results for $(\psi, \phi)$-weakly contractive mappings in ordered G-metric spaces. Comput. Math. Appl. 63(1), 298-309 (2012)

10. Aydi, H, Karapınar, E, Shatanawi, W: Tripled fixed point results in generalized metric spaces. J. Appl. Math. 2012, Article ID 314279 (2012)

11. Aydi, H, Karapinar, E, Shatanawi, W: Tripled common fixed point results for generalized contractions in ordered generalized metric spaces. Fixed Point Theory Appl. 2012, 101 (2012)

12. Banach, S: Sur les opérations dans les ensembles abstraits et leur application aux équations intégrales. Fundam. Math. 3, 133-181 (1922)

13. Ding, H-S, Li, L: Coupled fixed point theorems in partially ordered cone metric spaces. Filomat 25(2), 137-149 (2011)

14. Choudhury, BS, Kundu, A: A coupled coincidence point result in partially ordered metric spaces for compatible mappings. Nonlinear Anal. 73, 2524-2531 (2010)

15. Karapınar, E, Luong, NV, Thuan, NX, Hai, TT: Coupled coincidence points for mixed monotone operators in partially ordered metric spaces. Arabian Journal of Mathematics 1, 329-339 (2012)

16. Karapınar, E: Coupled fixed point theorems for nonlinear contractions in cone metric spaces. Comput. Math. Appl. 59 3656-3668 (2010)

17. Karapınar, E: Couple fixed point on cone metric spaces. Gazi University Journal of Science 24, 51-58 (2011)

18. Mustafa, Z, Aydi, H, Karapınar, E: On common fixed points in image-metric spaces using (E.A) property. Comput. Math. Appl. (2012). doi:10.1016/j.camwa.2012.03.051

19. Mustafa, Z, Obiedat, H, Awawdeh, F: Some fixed point theorem for mapping on complete G-metric spaces. Fixed Point Theory Appl. 2008, Article ID 189870 (2008)

20. Mustafa, Z, Khandaqji, M, Shatanawi, W: Fixed point results on complete G-metric spaces. Studia Sci. Math. Hung. 48, 304-319 (2011)

21. Mustafa, Z, Sims, B: Fixed point theorems for contractive mappings in complete G-metric spaces. Fixed Point Theory Appl. 2009, Article ID 917175 (2009)

22. Mustafa, Z, Shatanawi, W, Bataineh, M: Existence of fixed point results in G-metric spaces. Int. J. Math. Math. Sci. 2009, Article ID 283028 (2009)

23. Luong, NV, Thuan, NX: Coupled fixed point theorems in partially ordered G-metric spaces. Math. Comput. Model. 55, 1601-1609 (2012)

24. Shatanawi, W: Fixed point theory for contractive mappings satisfying $\Phi$-maps in G-metric spaces. Fixed Point Theory Appl. 2010, Article ID 181650 (2010)

25. Shatanawi, W: Some fixed point theorems in ordered G-metric spaces and applications. Abstr. Appl. Anal. 2011, Article ID 126205 (2011)

26. Shatanawi, W: Coupled fixed point theorems in generalized metric spaces. Hacet. J. Math. Stat. 40(3), $441-447$ (2011)

27. Shatanawi, W, Abbas, M, Nazir, T: Common coupled coincidence and coupled fixed point results in two generalized metric spaces. Fixed Point Theory Appl. 2011, 80 (2011)

28. Tahat, N, Aydi, H, Karapınar, E, Shatanawi, W: Common fixed points for single-valued and multi-valued maps satisfying a generalized contraction in G-metric spaces. Fixed Point Theory Appl. 2012, 48 (2012)

29. Fréchet, M: Sur quelques points du calcul fonctionnel. Rend. Circ. Mat. Palermo 22, 1-74 (1906). doi:10.1007/BF03018603

30. Ran, ACM, Reurings, MCB: A fixed point theorem in partially ordered sets and some application to matrix equations. Proc. Am. Math. Soc. 132, 1435-1443 (2004)

31. Nieto, JJ, Lopez, RR: Contractive mapping theorems in partially ordered sets and applications to ordinary differential equations. Order 22, 223-239 (2005)

32. Matthews, SG: Partial metric topology. Research Report 212. Dept. of Computer Science, University of Warwick (1992)

33. Guo, D, Lakshmikantham, V: Coupled fixed points of nonlinear operators with applications. Nonlinear Anal., Theory Methods Appl. 11, 623-632 (1987)

34. Fenwick, DH, Batycky, RP: Using metric space methods to analyse reservoir uncertainty. In: Proceedings of the 2011 Gussow Conference. Banff, Alberta, Canada (2011)

doi:10.1186/1029-242X-2012-200

Cite this article as: Karapınar et al.: On coupled fixed point theorems on partially ordered G-metric spaces. Journal of Inequalities and Applications 2012 2012:200. 